Original Research Paper

\title{
Pengkajian Kurikulum Program Studi di Pascasarjana Unram Ditinjau dari OBE dan Karakter BoK untuk Menunjang Akreditasi Unggul
}

\author{
Joni Rokhmat ${ }^{1,2,3}$, Fahruddin ${ }^{1}$, Asrin ${ }^{1}$, Ulpah$^{1}$, Lulu Il Muntaz ${ }^{1}$ \\ ${ }^{1}$ Department of Education Administration, Postgraduate Program, University of Mataram, Indonesia \\ ${ }^{2}$ Department of Science Education, Postgraduate Program, University of Mataram, Indonesia \\ ${ }^{3}$ Department of Physics Education, Teacher Training and Education Faculty, University of Mataram, Indonesia
}

https://doi.org/10.29303/jpmpi.v3i2.1218

Sitasi: Rokhmat, J., Fahruddin., Asrin., Ulfah \& Muntaz, L. II. (2021). Pengkajian Kurikulum Program Studi di Pascasarjana Unram Ditinjau dari OBE dan Karakter BoK untuk Menunjang Akreditasi Unggul. Jurnal Pengabdian Magister Pendidikan IPA, 5(1)

\author{
Article history \\ Received: 20 November 2021 \\ Revised: 30 Desember 2021 \\ Accepted: 5 Januari 2022 \\ *Corresponding Author: Joni \\ Rokhmat, University of \\ Mataram, Mataram, Indonesia; \\ Email: joni.fkip@unram.ac.id
}

\section{Pendahuluan}

Pengabdian Kepada Masyarakat (PKM) termasuk salah satu unsur dari pelaksanaan Tri Dharma Perguruan Tinggi. Dalam KPM kali ini, kegiatan dilakukan dalam rangka mendukung upaya peningkatan kualifikasi akreditasi program studi di lingkungan Pascasarjana Unram menuju terakreditasi dengan status unggul. Di Pascasarjana Unram terdapat tiga Program Studi, yaitu Magister

\begin{abstract}
Kurikulum berbasis (Outcome Based Education) OBE dan berkarakter (Body of Knowledge) BoK menjadi keniscayaan bagi suatu program studi untuk memperoleh predikat unggul dalam akreditasi. Tujuan pengabdian ini melakukan pengkajian dokumen kurikulum program studi di lingkungan Pascasarjana Universitas Mataram ditinjau dari OBE dan BoK. Metode pelaksanaan melakukan analisis cermat dokumen kurikulum yang digunakan di tiga program studi, Magister Pendidikan IPA, Magister Administrasi Pendidikan, dan Magister Pertanian Lahan Kering. Pengkajian difokuskan pada profil lulusan beserta capaiannya yang terdiri atas capaian lulusan, capaian matakuliah, hingga sub-capaian matakuliah, serta relevansi setiap matakuliah dalam mendukung setiap capaian tersebut. Hasilnya menunjukkan pada ketiga program studi tersebut belum secara optimal memperlihatkan orientasi OBE, serta dalam dokumen kurikulum belum disajikan secara ekaplisit karakter BoK baik dengan cara membangun garis besar yang menghubungkan capaian keterampilan, sikap, dan pengetahuan atau mengkompilasi secara rinci teori, metodologi, teknologi, dan prosedur. Dalam rangka menunjang akreditasi unggul direkomendasikan agar setiap program studi segera melakukan rekonstruksi kurikulum menuju berbasis OBE secara utuh pada profil, CPL, CPPS, dan CPMK, serta dalam kurikulum tersebut menunjukkan melalui display karakter BoK menggunakan salah satu pendekatan di atas.
\end{abstract}

Keywords: Kurikulum program studi, Pascasarjana Universitas Mataram, Outcom Based Education, Body of Knowledge, akreditasi unggul.

Pendidikan IPA, Magister Administrasi Pendidikan, dan Magister Pertanian Lahan Kering. Hinga saat ini, ketiga program studi tersebut terakreditadi B. Dalam rangka mendukung upaya mewujudkan visi Universitas Mataram menjadi lembaga pendidikan tinggi berbasis riset berdaya saing internasional tahun 2025 (Sunarpi, 2016), sesuai dengan kemampuannya, program studi di lingkungan Pascasarjana Unram sudah seharusnya berusaha meningkatkan status akreditasinya menuju status unggul. 
Salah satu tahapan upaya meningkatkan status akreditasi di atas adalah menyempurnakan kurikulum sebagai pilar utama penyelenggaraan pendidikan. Untuk mencapai akreditasi dengan status peringkat unggul, salah satu syarat yang harus dipenuhi adalah memiliki nilai akreditasi $\geq$ 361. Dalam upaya mendukung pencapaian nilai akreditasi tersebut, kriteria ke-6, dari sembilan kriteria, adalah "pendidikan" yang memiliki bobot mencapai 15,9\% (Sasongko, 2019: 13-14). Selanjutnya, sebagai pilar dari pendidikan itu sendiri adalah kurikulum.

Sejauh ini, kurikulum yang dikembangkan pada program studi di lingkungan Pascasarjana Unram, sepengetahuan tim pengabdian, belum secara eksplisit mengarahkan pada kurikulum yang berbasis outcome based education (OBE) dengan karakter body of knowledge (BoK) yang melekat.

OBE didefinisikan sebagai suatu cara merancang, mengembangkan, menyampaikan dan mendokumentasikan instruksi dalam kaitannya dengan tujuan dan hasil yang diinginkan. Outcome atau hasil merupakan faktor penting dalam merancang kurikulum yang dikembangkan dari hasil yang perlu didemonstrasikan oleh siswa (Husein, 2021).

Selanjutnya, kurikulum berkarakter BoK dimaksudkan kurikulum yang merepresentasikan peta ilmu yang dijabarkan melalui matakuliahmatakuliah. Dalam kurikulum BoK, setiap matakuliah memiliki kaitan dengan matakuliah lain sehingga membangun suatu jejaring keilmuan yang ingin dikembangkan melalui penyelenggaraan pendidikan dalam program studi tersebut. Dengan kata lain, kurikulum itu bukan sebagai kumpulan matakuliah tetapi sebagai jaringan matakuliah (Husein, 2021).

Berdasarkan hasil studi awal, melalui interaksi informal tim pengabdian dengan penyelenggara program studi di lingkungan Pascasarjana Unram maupun melalui kegiatan lain yang kebetulan dilaksanakan di program studi mitra, diperoleh informasi bahwa kurikulum yang dikembangkan belum secara optimal menjadikan OBE sebagai basis. Selain itu, karakter BoK dalam kurikulum tersebut juga belum secara eksplisit dimunculkan baik dalam bentuk dokumen tersimpan maupun melalui display melalui papan informasi maupun media sosial.

Sesuai dengan dua paparan di atas, maka dalam kegiatan pengabdian ini dirumuskan tiga masalah pengabdian sebagai berikut: 1. Pada pengembangan kurikulum program studi di lingkungan Pascasarjana Unram, apakah sudah secara eksplisit menempatkan OBE sebagai basis? Apakah matakuliah-matakuliah pendukung kurikulum program studi di lingkungan Pascasarjana Unram secara eksplisit menunjukkan peta keilmuan yang ingin dikembangkan? 3. Bagaimanakah rekomendasi-rekomendasi penyempurnaan kurikulum di program studi di lingkungan Pascasarjana Unram agar berbasis OBE dan memiliki karakter peta keilmuan (BoK)?

Tujuan pengabdian pada masyarakat ini adalah: Mengidentifikasi dan menganalisis kurikulum program studi di lingkungan Pascasarjana Unram. Mengidentifikasi dan menganalisis penempaan OBE sebagai basis dalam kurikulum program studi di lingkungan Pascasarjana Unram, dan Memberi rekomendasi berdasar hasil analisis penyempurnaan kurikulum di program studi di lingkungan Pascasarjana Unram supaya berbasis OBE dan berkarakter BoK.

Kegiatan pengabdian ini diharapkan dapat memberikan manfaat, bagi program studi di lingkungan Pascasarjana Universitas Mataram: Menyempurnakan kurikulum agar secara optimal menempatkan OBE sebagai basis. Menyempurnakan kurikulum agar memiliki karaktar BoK, dan Memiliki kurikulum yang mendukung upaya reakreditasi unggul..

\section{Metode}

Untuk memecahkan masalah di atas perlu diadakan pengabdian kepada program studi di lingkungan Pascasarjana Unram tentang pemahaman kurikulum berbasis OBE, kurikulum berkarakter BoK, dan bagaimana menyiapkan kurikulum dalam rangka penyiapan reakreditasi menuju peringkat unggul. Dalan pengabdian ini diawali dengan analisis situasi program studi mitra kemudian dilanjutkan dengan kegiatan identifikasi kurikulum yang digunakan, serta identifikasi rekomendasi-rekomendasi esensial untuk penyempurnaannya, dan terakhir dilakukan evaluasi hasil kegiatan.

Secara rinci, tahapan pemecahan masalah tersebut adalah: 1) Kondisi saat ini, Kurikulum belum berbasis OBE \& berkarakter BoK; Kegiatan, Dilakukan kajian kurikulum program studi Pascasarjana Unram; Diharapkan, Penyelenggara 
program studi memiliki pemahaman kurikulum berbasis OBE \& berkarakter BoK; 2) Kondisi saat ini, Penyelenggara Prodi belum memiliki pemahaman optimal pengembangan kurikulum berbasis OBE \& berkarakter BoK; Kegiatan, Penyusunan dokumen strategi pengembangan kurikulum berbasis OBE \& berkarakter BoK; Diharapkan, Penyelenggara program studi termotivasi menyusun kurikulum berbasis OBE \& berkarakter BoK; 3) Kondisi saat ini, Penyelenggara Prodi belum pernah mengembangkan kurikulum berbasis OBE \& berkarakter BoK; Kegiatan, Sosialisasi dan pembagian dokumen kepada penyelenggara program studi; Diharapkan, Ada penyelenggara program studi yang berencana reakreditasi menuju peringkat unggul.

Kegiatan pengabdian pada masyarakat ini melibatkan beberapa anggota pengelola Gugus Penjaminan Muru Pascasarjana Unram yang beberapa di anaranya juga menjadi penyelenggara program studi di lingkungan Pascasarjana Unram. Adapun yang menjadi sasaran kegiatan pengabdian adalah kurikulum program studi di lingkungan Pascasarjana Unram.

Dilematika peningkatan kualitas program studi sudah menjadi keniscayaan tidak hanya dipikirkan oleh pihak penyelenggara program studi, tetapi menjadi permasalahan semua unsur yang terkait, seperti Gugus Penjaminan Mutu, Pimpinan Pascasarjana, Piminan Universitas, serta seluruh personal yang terlibat, dosen dan tenaga kependidikan. Status akreditasi berpotensi mencapai peringkat unggul apabila komponen pendukungnya telah dikembangkan secara optimal. Komponen pendukung tersebut mencakup kurikulum. Kurikulum yang diharapkan dapat mendukung tercapainya peringkat akreditasi unggul adalah kurikulum yang memiliki basis Outcome Based Education (OBE) dan memiliki karakter Body of Knowledge (BoK), yaitu kurikulum yang memperlihatkan peta keilmuan yang ingin dikembangkan dalam penyelenggaraan pendidikan di program studi tersebut. Penyempurnaan kurikulum yang ada menjadi kurikulum berbasis OBE dan berkaraker BoK dapat dilakukan dengan didahului proses kajian terhadap kurikulum itu dan selanjutnya dibuat rekomendasi-rekomendasi esensial. Melalui pengabdian ini, diharapkan dapat dikaji kurikulum yang sudah ada, kemudian disusun rekomendasi, dan akhirnya dilakukan penyempurnaan sehingga tersusun kurikulum baru yang memenuhi syarat untuk mendukung reakreditasi program studi menuju satus peringkat unggul.

Pengabdian ini menggunakan metode analisis dokumen, FGD internal tim pengabdian, dan penduatan dokumen rekomendasi penyempurnaan kurikulum, serta desiminasi dokumen kepada penyelenggara program studi di lingkungan Pascasarjana Unram.

Evaluasi ditujukan untuk memanfaatkan informasi yang diperoleh sebagai acuan dalam menentukan kegiatan selanjutnya. Evaluasi ini direncanakan dilakukan pada bagian proses pelaksanaan dan bagian akhir kegiatan dengan cara mengidentifikasi respon penyelenggara program studi. Evaluasi tentang respon penyelenggara program studi dijaring melalui wawanara semiterbuka.

\section{Hasil dan Pembahasan}

Hasil Kegiatan: Peninjauan kurikulum program studi di lingkungan Pascasarjana Universitas Mataram difokuskan pada dua hal, yaitu penggunaan Outcome Based Education (OBE) sebagai dasar, serta kesatuan inter-korelasi setiap matakuliah dengan matakuliah lainnya dalam rangka memfasilitasi terwujudnya cita-cita kurikulum membentuk lulusan yang sesuai dengan profil yang telah ditetapkan.

\section{A. Peninjauan Outcome Based Education (OBE) Sebagai Basis Penyusunan Kurikulum}

Sebagaimana disebutkan dalam permendikbud Nomor 3 Tahun 2020 Pasal 5 Ayat (1) bahwa standar kompetensi lulusan merupakan kriteria minimal tentang kualifikasi kemampuan lulusan yang mencakup sikap, pengetahuan, dan keterampilan yang dinyatakan dalam rumusan Capaian Pembelajaran Lulusan. Selanjutnya, dalam Ayat (3) disebutkan bahwa Rumusan capaian Pembelajaran lulusan tersebut wajib: a) mengacu pada deskripsi capaian Pembelajaran lulusan KKNI; dan b) memiliki kesetaraan dengan jenjang kualifikasi pada KKNI.

Hasil capaian pembelajaran yang dicantumkan dalam dokumen kurikulum di program studi 1) Magister Administrasi Pendidikan, 2) Magister Pertanian Lahan Kering, 
dan 3) Magister Pendidikan IPA didapat hasil analisis sebagai berikut:

1. Pada kurikulum program studi Magister Administrasi Pendidikan

Kompetensi lulusan yang diuraikan kedalam tiga sub, yaitu kompetensi utama, kompetensi pendukung, dan kompetensi lainya secara keseluruhan tidak mencerminkan struktur capaian berbasis Outcome Based Education atau OBE. Analisis lebih lanjut juga belum mencerminkan keutuhan adopsi capaian pembelajaran dari rujukan yang disyaratkan, yaitu Peraturan Menteri Pendidikan dan Kebudayaan (Permendikbud) nomor 3 tahun 2020 dan Peraturan Presiden (Perpres) nomor 8 tahun 2012.

2. Pada kurikulum program studi Magister Pertanian Lahan Kering

Dalam profil lulusan unsur OBE sudah muncul tetapi perlu dipertimbangkan lagi aspek OBE yang lebih luas, seperti mampu mengelola pemanfaatan lahan kering, pengusaha pertanian berbasis lahan kering, dan sebagainya. Namun demikian, dalam capaian pembelajaran tidak ada satupun capaian yang berbasis OBE tetapi cenderung mendasarkan pada perpres nomor 8 tahun 2012 meskipun itu hanya sepertiganya, yang lainnya tidak mencerminkan capaian pembelajaran yang berbasis pada permedikbud nomor 3 tahun 2020 maupun perpres nomor 8 tahun 2012.

3. Pada kurikulum program studi Magister Pendidikan IPA

Serupa dengan pada Magister Pertanian Lahan Kering, dalam profil lulusan unsur OBE sudah muncul tetapi perlu dipertimbangkan lagi aspek OBE yang lebih luas, seperti mampu mengelola pendidikan IPA. Capaian pembelajaran sudah mendasarkan pada permendikbud nomor 3 tahun 2020, khsusnya aspek sikap, dan perpres nomor 8 tahun 2012 khususnya rumusan capaian pembelajaran terkait dengan Kerangka Kualifikasi Nasional Indonesia (KKNI) lebel 8. Namun demikian, dalam rangka menuju program studi unggul, capaian pembelajaran juga harus berbasis OBE. Hal serupa muncul juga dalam Capaian Pembelajaran Program Studi, semua rumusan belum ada yang berbasis OBE. Pandangan kami, tim pengabdian, harus tetap menetapkan capaian pembelajaran berbasis OBE.
Hasil analisa pada tiga program studi di atas cenderung pada dokumen kurikulum aspek profil lulusan, capaian pembelajaran lulusan, dan capaian pembelajaran program studi. Perlu diperhatikan bahwa dalam rangka menuju program studi terakreditasi unggul maka pada ketiga aspek kurikulum tersebut tetap menetapkan OBE sebagai basis dalam menyusun rumusan capaian. Satu lagi, dalam Capaian Pembelajaran Mata Kuliah (CPMK) juga tetap ditampilkan capaian yang berbasis OBE. Gagasan ini setidaknya dapat dipertimbangkan oleh setiap tim pengembang kurikulum di program studi dalam melakukan penyusunan kurikulum.

\section{B. Peninjauan Body of Knowledge (BoK) Sebagai Karakter Kurikulum}

Menurut Greenfeld Joshua 2010 Body of Knowledge (BoK) dapat didefinisikan dengan dua pendekatan. Pertama, dengan membangun garis besar keterampilan, attitude, dan pengetahuan yang perlu bagi seseorang untuk paham dan mampu menjadi ahli professional. Kedua, dengan mengkompilasi secara rinci teori, metodologi, teknologi, dan prosedur yang perlu dikuasai pada praktik para professional. Dalam peninjauan ini, BoK mendasarkan pada salah satu dari dua pendekatan di atas. Artinya, apabila dalam struktur kurikulum sudah ditampilkan hubungan satu dengan lainnya, antara keterampilan, attitude, dan pengetahuan, atau ditampilkan bentuk rinci kompilasi dari teori, metodologi, teknologi, dan prosedur maka dikatakan bahwa kurikulum tersebut sudah memiliki karakter Body of Knowledge. Wujud dari dua pendekatan BoK juga dapat ditampilkan melalui hubungan inter-relasi setiap matakuliah dengan capaian pembelajaran pada tiga ranah tersebut, attitude atau sikap, pengetahuan, dan keterampilan.

Hasil analisis kurikulum di tiga prodi, Magister Administrasi Pendidikan, Magister Pertanian Lahan Kering, dan Magister Pendidikan IPA, ketiganya tidak memperlihatkan salah satu dari dua pendekatan sebagai penciri karakter BoK. Dengan demikian, untuk memutuskan apakah kurikulum di setiap program studi tersebut apakah sudah berkarakter BoK atau belum, perlu dianalisis lanjut seluruh capaian pembelajaran dan matakuliah melalui salah satu dari dua pendekatan di atas. 


\section{Kesimpulan}

Hasil peninjauan kurikulum di tiga program studi Pascasarjana Universitas Mataram, yaitu program studi Magister Administrasi Pendidikan (MAP), Magister Pertanian Lahan Kering (MPLK), dan Magister Pendidikan IPA (MP-IPA) disimpulakan bahwa: 1) secara umum kurikulum yang disusun belum sepenuhnya berbasis Outcome Based Education (OBE). Pada MAP belum ada capaian pembelajaran yang rumusannya berbasis OBE, pada MPLK dan MP-IPA rumusan OBE muncul pada profil lulusan. Perlu diperhatikan bahwa capaian berbasis OBE harus dimunculkan pada profil lulusan, capaian pembelajaran lulusan (CPL), capaian pembelajaran program studi (CPPS), hingga pada capaian pembelajaran mata kuliah (CPMK). 2) Ketiga program studi (MAP, MPLK, dan MP-IPA) belum menyusun paparan yang secara eksplisit memperlihatkan karakter Body of Knowledge (BoK).

Dalam rangka menuju akreditasi unggul, disarankan dua hal berikut: 1) Setiap prodi perlu melakukan rekonstruksi kurikulum agar sepenuhnya berbasis OBE. 2) Dalam dokumen kurikulum sebaiknya disajikan karakter Body of Knowledge dengan salah satu pendekatan, yaitu membangun gasir besar yang menghubungkan keterampilan, attitude atau sikap, serta pengetahuan atau mengkompilasi secara rinci teori, metodologi, teknolodi, dan prosedur.

\section{Daftar Pustaka}

Husein, M. F., 2021. PENTINGNYA OUTCOME BASED EDUCATION DALAM AKREDITASI/ SERTIFIKASI INTERNASIONAL. PPT presentasi sosialisasi akreditasi/sertifikasi AUNQA.

No name, 2021. Outcome Based Education System. Diakses tanggal 30 April 2021 melalui URL:

https://www.bing.com/search?q=outcome + based+education+obe $\&$ cvid $=2 \mathrm{a} 5 \mathrm{~d} 477 \mathrm{a} 4$ 6e14252b6e462d1268f2fe2\&aqs=edge. 1 . $017.11816 \mathrm{j} 0 \mathrm{j} 4 \& \mathrm{FORM}=\mathrm{ANAB} 01 \& \mathrm{PC}=$ $\underline{\mathrm{U} 531}$
Sasongko, Dwiwahju, 2019. Akreditasi Program Studi, Pedoman Penilaian. Jakarta: BAN-PT, Majelis Akreditasi

Sunarpi, 2016. Rencana Induk Penelitian (RIP) Universitas Mataram Tahun 2016-2020. Mataram: Unram Press 